\title{
Summer Arctic sea ice albedo in CMIP5 models
}

\author{
T. Koenigk ${ }^{1}$, A. Devasthale ${ }^{2}$, and K.-G. Karlsson ${ }^{2}$ \\ ${ }^{1}$ Rossby Centre, Swedish Meteorological and Hydrological Institute, 60176 Norrköping, Sweden \\ ${ }^{2}$ Atmospheric Remote Sensing Unit, Swedish Meteorological and Hydrological Institute, 60176 Norrköping, Sweden \\ Correspondence to: T. Koenigk (torben.koenigk@smhi.se)
}

Received: 10 September 2013 - Published in Atmos. Chem. Phys. Discuss.: 30 September 2013

Revised: 8 January 2014 - Accepted: 9 January 2014 - Published: 20 February 2014

\begin{abstract}
Spatial and temporal variations of summer sea ice albedo over the Arctic are analyzed using an ensemble of historical CMIP5 model simulations. The results are compared to the CLARA-SAL product that is based on long-term satellite observations. The summer sea ice albedo varies substantially among CMIP5 models, and many models show large biases compared to the CLARA-SAL product. Single summer months show an extreme spread of ice albedo among models; July values vary between 0.3 and 0.7 for individual models. The CMIP5 ensemble mean, however, agrees relatively well in the central Arctic but shows too high ice albedo near the ice edges and coasts. In most models, the ice albedo is spatially too uniformly distributed. The summer-tosummer variations seem to be underestimated in many global models, and almost no model is able to reproduce the temporal evolution of ice albedo throughout the summer fully. While the satellite observations indicate the lowest ice albedos during August, the models show minimum values in July and substantially higher values in August. Instead, the June values are often lower in the models than in the satellite observations. This is probably due to too high surface temperatures in June, leading to an early start of the melt season and too cold temperatures in August causing an earlier refreezing in the models. The summer sea ice albedo in the CMIP5 models is strongly governed by surface temperature and snow conditions, particularly during the period of melt onset in early summer and refreezing in late summer.

The summer surface net solar radiation of the ice-covered Arctic areas is highly related to the ice albedo in the CMIP5 models. However, the impact of the ice albedo on the sea ice conditions in the CMIP5 models is not clearly visible. This indicates the importance of other Arctic and large-scale processes for the sea ice conditions.
\end{abstract}

\section{Introduction}

Arctic climate has strongly changed in the last decades (ACIA, 2005). The observed warming in the Arctic regions is about twice the rate of the global mean warming (ACIA, 2005; IPCC, 2007; Richter-Menge and Jeffries, 2011). The warming is concurrent with an extension of melting season (Markus et al., 2009) and a rapid decline of Arctic sea ice extent in the last decades (Comiso et al., 2008; Stroeve et al., 2012) with a recent extreme September minimum in 2012 (Devasthale et al., 2013; Guemas et al., 2013). Markus et al. (2009) found also an increase of melting season in recent decades. Future projections indicate a continuous climate change in the Arctic in the next decades (Vavrus et al., 2012; Koenigk et al., 2013).

The observed Arctic temperature amplification compared to lower latitudes has led to an intensive discussion on the role of the surface albedo. Riihelä et al. (2013b) showed in a recent study that the observed surface albedo of the remaining Arctic ice area has decreased significantly since 1982. Besides the ice-albedo feedback, the importance of enhanced meridional energy transport (Graversen et al., 2008), changes in clouds and water vapor (Graversen and Wang, 2009; Liu et al., 2008), the weak vertical mixing in the Arctic winter inversion (Bintanja et al., 2011) and enhanced ocean heat transport into the Arctic (Spielhagen et al., 2011; Koenigk and Brodeau, 2013) have been discussed as possible sources for Arctic temperature amplification. However, it seems to be beyond question that the ice-albedo feedback is an important contributor to Arctic temperature amplification and changes in sea ice conditions (Serreze et al., 2009; Winton, 2006).

The surface albedo is strongly affecting the radiation budget of the earth. Li et al. (2006) showed that already small changes in the surface albedo have a large impact on the 
climate. This is particularly true for the Arctic since temporal and spatial variations of surface albedo are extremely high in the Arctic; values can vary between around 0.8 for snow-covered ice and around 0.5 for melting ice and are even substantially lower if melt ponds are formed on the ice or if the ice becomes very thin and totally melts (Laine, 2004). Refreezing or snowfalls can lead to rapid albedo increases. These temporal and spatial variations on small scales make modeling the albedo of the Arctic ice/snow system challenging. Hodson et al. (2013) showed that the cross-model variations of ice albedo contribute to the large uncertainties in the Arctic climate as simulated by global climate models. Liu et al. (2007) analyzed the albedo in the Arctic by using SHEBA data (Surface Heat Budget of the Arctic Ocean Project, Utall et al., 2002) as input for four global climate model albedo schemes and compared the results to the observed SHEBA albedo. The values varied substantially from model to model, indicating substantial differences in the model albedo parameterizations.

In a recent study, Karlsson and Svensson (2013) showed that Arctic mean surface albedo varies strongly among CMIP5 models with large consequences for the radiation balance. This, among other reasons, further warrants detailed evaluation of the spatiotemporal variability of surface albedo over the Arctic. The recently released surface albedo product from the Satellite Application Facility on Climate Monitoring (CM-SAF) clouds, albedo and radiation data set (CLARA-SAL, Riihelä et al., 2013a; Karlsson et al., 2013) and sea ice concentration from the Ocean and Sea Ice Satellite Application Facility (OSI-SAF) data set (Eastwood et al., 2010) allow such detailed evaluation of CMIP5 models. This is the main focus of the present study. Furthermore, we discuss the main sources for the cross-model variations and possible implications for the Arctic climate.

\section{Model simulations and data}

\subsection{Model data}

Historical simulations from 21 CMIP5 models are analyzed. One ensemble member from each model has been used, and all models were selected from the CMIP5 database where all relevant variables were available (http://esgf-data.dkrz.de/ esgf-web-fe/).

The surface albedo in the models was calculated from monthly mean values of the downward and upward surface solar radiation (as done in Karlsson and Svensson, 2013). Monthly mean sea ice concentration was used to extract the sea ice albedo for the ice-covered part of each grid box:

$\alpha_{\text {surf }}=\alpha_{\text {ice }} \cdot A_{\text {ice }}+\alpha_{\text {water }} \cdot\left(1-A_{\text {ice }}\right)$

with $\alpha_{\text {surf }}=$ surface albedo, $\alpha_{\text {ice }}=$ albedo of the ice - covered part,

$\alpha_{\text {water }}=$ albedo of the ice - free part, $A_{\text {ice }}=$ ice - covered area
Hereby, we assumed a constant surface albedo of the icefree part of 0.07 . We only considered sea ice albedo for grid points exceeding $15 \%$ ice concentration in order to be consistent with the results from the satellite product (Sect. 2.2).

We used ice concentration, ice thickness, snow depth on ice and surface temperature from the models to analyze ice albedo variations further. Note that snow depth was only available for 16 out of the 21 global models. For better comparison, all model data have been interpolated on a common grid $\left(1^{\circ} \times 1^{\circ}\right)$.

The period 1982-2005 was used for comparison with satellite data of the same period. We not only compare in detail the spread among single models but also compare the model ensemble mean to satellite data. It has been shown that the multi-model ensemble mean almost always outperforms single model results by compensating for differences due to natural variations and to model errors. We cannot expect a single climate model to reproduce the single realization of the reality exactly, and the CMIP5 model mean helps to set the result in the wider context. A realistic ensemble mean could provide certain confidence in the models despite strong spread among models. However, for reducing uncertainties it is necessary to analyze the single models since the ensemble mean is not based on a set of consistent physics.

\subsection{Observations and data}

We used the surface albedo product from the Satellite Application Facility on Climate Monitoring (CM-SAF) clouds, albedo and radiation data set (CLARA-SAL, Riihelä et al., 2013a; Karlsson et al., 2013) and sea ice concentration from the Ocean and Sea Ice Satellite Application Facility (OSISAF) data set (Eastwood et al., 2011) as comparison for the model data. Both data sets are available on a $0.25^{\circ}$ grid. The surface albedo is available for 1982-2009 and ice concentration from 1979 to 2009. The CLARA-SAL surface albedo is defined as the inherent surface reflectance and presents the mean albedo in each grid box, averaging over the ice and ocean parts of the box. Figure 1 shows an example for the CLARA-SAL surface albedo and the CMIP5 ensemble mean. While the large-scale patterns look similar, the satellite data provide much more detailed information and resolve finer transition from open ocean to sea ice.

To extract the sea ice albedo from the CLARA-SAL data, we used the ice concentration from the OSI-SAF product and split the albedo in the ice-covered part and the ice-free part, assuming a constant albedo of 0.07 as for the model simulations. We will refer to this ice albedo based on CLARA-SAL surface albedo and OSI-SAF ice concentration as CLARASAL ice albedo.

The uncertainties of sea ice concentrations are largest in summer when it is difficult to distinguish between open water and water on ice. This is particular the case for areas with low ice concentrations; therefore we excluded all grid points with an ice concentration below $15 \%$ from the analysis. 

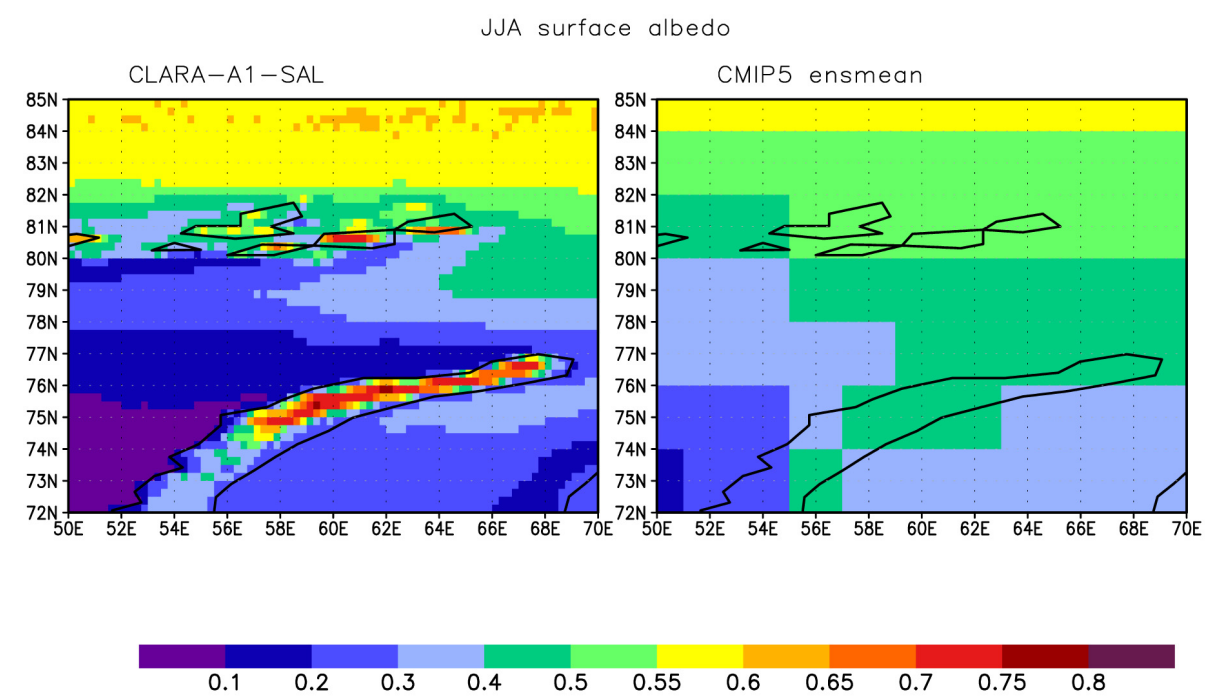

Fig. 1. Summer (JJA average) surface albedo in the northeastern Barents Sea region, averaged over 1982-2005, in CLARA-SAL on a $0.25^{\circ} \times 0.25^{\circ}$ grid and in the CMIP5 ensemble mean interpolated on a $2^{\circ} \times 2^{\circ}$ grid

The CLARA-SAL surface albedo has been validated by Riihelä et al. (2010) using observed values from the Tara Experiment. Time-averaged products show an accuracy of $5-10 \%$.

No comprehensive observational data sets exist for surface temperature, snow depth and ice thickness in the Arctic Ocean area. We thus used surface temperature from the ERA-Interim reanalysis (Dee et al., 2011) as comparison for the model results. Note that the reanalysis also has relatively large uncertainties since the Arctic is a data-sparse region. The surface temperature in the central Arctic in the ERAInterim reanalysis is mainly determined by the state of the surface, and Lüpke et al. (2010) and Jakobson et al. (2012) highlighted uncertainties in the near-surface temperatures. Ice thickness and snow depth are compared to results from the literature.

\section{Results}

\subsection{Sea ice conditions in the CMIP5 models}

The Arctic surface albedo in the CMIP5 climate models might depend strongly on the distribution of sea ice concentration and thickness in the models. Thus, this section presents the spatial distributions of the Arctic ice conditions in the global models before discussing the albedo in the following sections.

The sea ice extent in the Arctic in the CMIP5 model ensemble shows a very large spread although some improvements are observed compared to the CMIP3 ensemble (Stroeve et al., 2012; Massonnet et al., 2012). Figure 2 shows the spatial distribution of September sea ice concentration in the 21 CMIP5 models used in this study and in the satellite observations. The ice edge is relatively well simulated in the CMIP5 model ensemble mean. However, ice concentration is too small in the central Arctic, and ice extends slightly too far to the coasts, particularly in the Kara Sea. Variations among models are very large showing both strongly underestimated and overestimated Arctic ice areas. Also the distribution of ice concentration varies strongly among models. Even models with realistic sea ice extent and sea ice trend (Massonnet et al., 2012) do not necessarily show an entirely realistic ice distribution (e.g., ACCESS1.3 and MPI-ESM-MR). They tend, like a number of other models as well (CanCM4, Can ESM2, HadCM3, MPI-ESM-LR), to simulate highest ice concentrations in the middle of the Arctic Basin or in the Beaufort Sea and not along the north coasts of Greenland and the Canadian Archipelago as observed by satellites.

The large spread of ice conditions among models is also obvious in the ice thickness distribution (Fig. 3). The central Arctic ice thickness varied between about $1 \mathrm{~m}$ and $4 \mathrm{~m}$ at the end of the 20th century. A number of models simulate the thickest ice in the central Arctic (CanCM4, CanESM2, CSIRO-Mk3-6-0, FGOALS-g2, HadCM3, INMC4), while others show a secondary maximum near the Siberian coast (CMCC-CESM, EC-Earth, MIROC5. NorESM1-M). Although the distribution of ice thickness is not well observed, observation-based estimates suggest an ice thickness distribution (Belchansky et al., 2008; Rothrock et al., 2003; Kwok and Cunningham, 2008), which compares relatively well with the CMIP5 ensemble mean.

The reasons for the large spread in sea ice conditions among models are probably wide and include varying oceanic and atmospheric heat transports into the Arctic, varying Arctic atmospheric and oceanic circulations, differences in Arctic cloud and radiation processes and different 


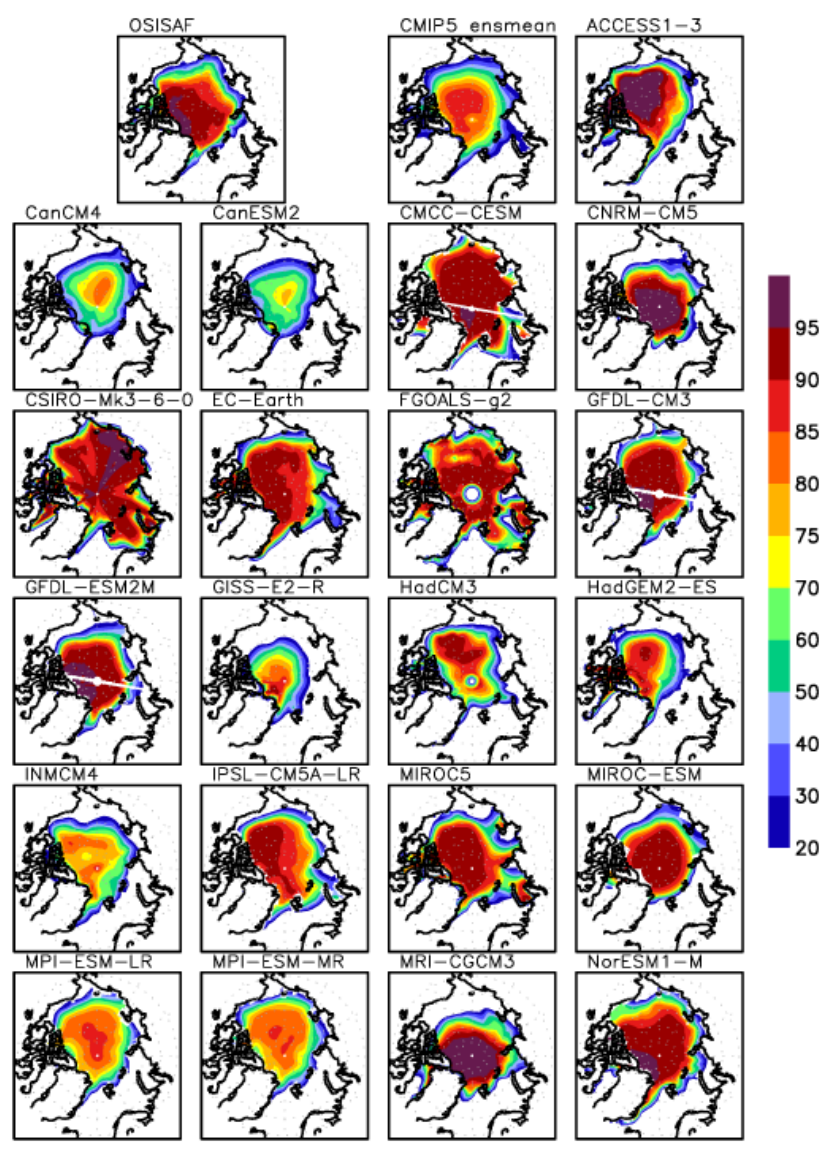

Fig. 2. September sea ice concentration in the OSISAF satellite product, CMIP5 ensemble mean and individual CMIP5 models, averaged over the period 1982-2005.

parameterizations in the sea ice models. Small differences among models in one or more of these variables might lead to large differences in the simulated Arctic climate since many feedback mechanisms (e.g., sea ice albedo, water vapor, lapse rate, cloud) are active in the Arctic and can amplify the signal.

\subsection{Surface albedo}

Figure 4 shows the summer mean (mean over June, July, and August) surface albedo in CLARA-SAL and the CMIP5 models. Since the surface albedo is an average over the entire grid box, it shows a mixture of ice albedo and water albedo. This means the differences in ice concentrations in the CMIP5 models shown in Sect. 3.1 might partly explain the cross-model spread in summer surface albedos and deviations from the satellite observations.

Highest summer surface albedo in CLARA-SAL occurs between the North Pole and the coasts of northern Greenland and the Canadian Archipelago with values of up to 0.65. Towards the ice edges and the coasts of Alaska and Siberia,

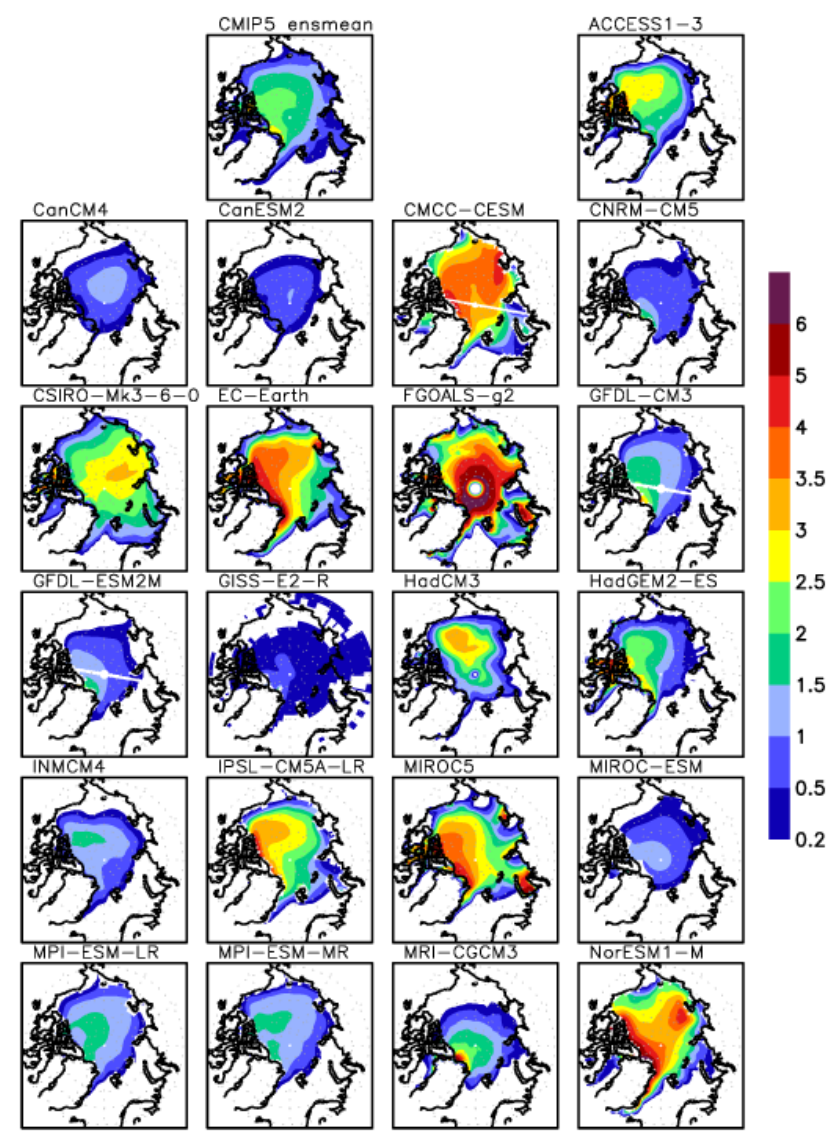

Fig. 3. September sea ice thickness in meters in the CMIP5 ensemble mean and individual CMIP5 models, averaged over the period 1982-2005.

surface albedo is reduced and falls below 0.5 , partly due to more open water in these areas.

The ensemble mean of the CMIP5 models simulates the observed distribution relatively well. However, surface albedo varies strongly among models. The majority of models show summer values between 0.55 and 0.7 in the central Arctic, but a few outliers simulate substantially lower or higher albedo values.

The spatial pattern of the observed surface albedo is relatively well simulated in most models with highest albedos in the area between North Pole and northern Greenland/Canadian Archipelago. However, in a few models the maximum is moved away from the Greenland coast into the interior of the central Arctic. These are those models where also the sea ice concentration is highest in the interior of the Arctic away from Greenland's north coast. There is a clear relation between the spatial distribution of sea ice concentration and surface albedo in each individual model. However, we cannot generally state that models with a high (low) ice concentration also show a high (low) surface albedo. 


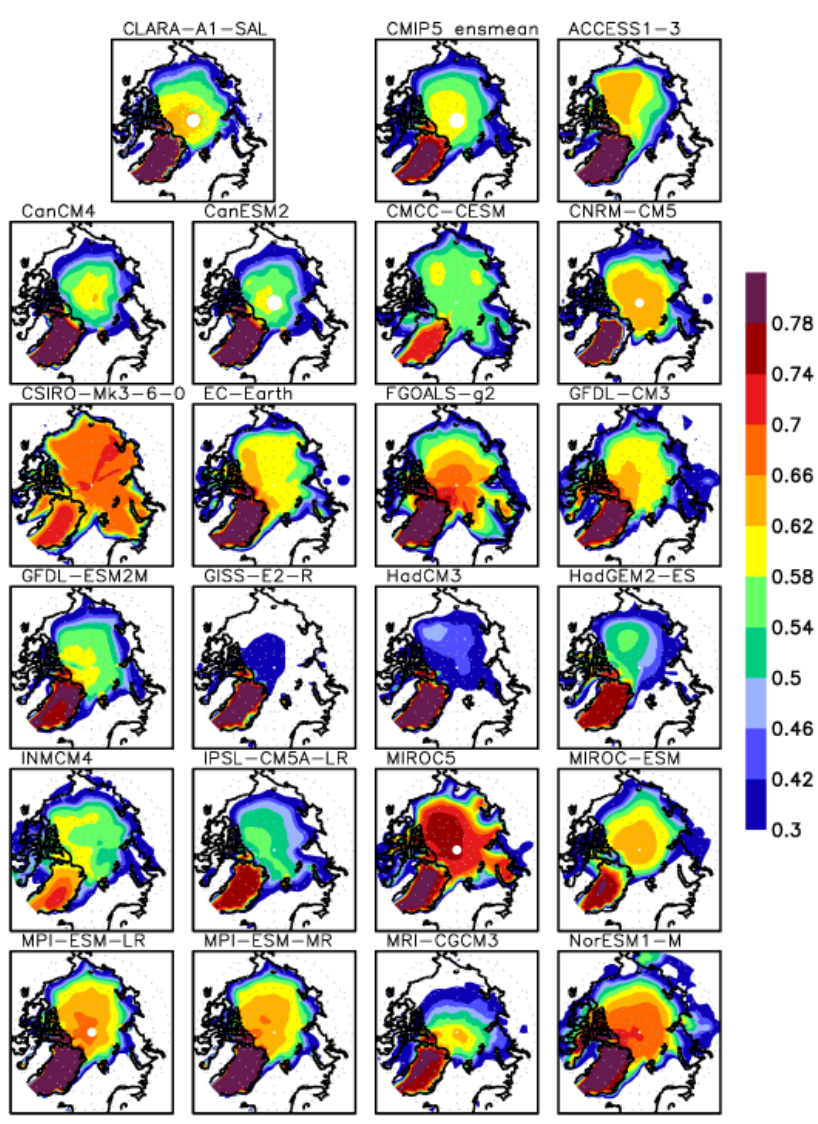

Fig. 4. Summer-averaged (JJA) surface albedo in CLARA-SAL, the CMIP5 ensemble mean and the individual CMIP5 models. Shown is the time average over the period 1982-2005.

A number of models underestimate the observed gradient of albedo in the Arctic and show a too uniform surface albedo over large parts of the central Arctic.

The differences among models and between models and CLARA-SAL are substantially larger for single months than for the summer average (not shown). In June, surface albedo is already strongly reduced in a few models due to earlier onset of snowmelt and ice melt and warmer surface temperatures, while the Arctic is still snow-covered in others, leading to a much higher albedo. CLARA-SAL shows still high albedo values in the central Arctic and north of Greenland and the Canadian Archipelago; here values exceed 0.7, but the albedo is substantially reduced towards the coasts. Only a few models are able to reproduce this strong gradient towards lower Arctic latitudes. In July, the satellite observations show maximum values of slightly above 0.6 near the North Pole but much smaller values near the ice edges and coasts. Most models simulate surface albedos between 0.54 and 0.58 in the central Arctic and slightly below 0.4 near the ice edges, but a few models have substantially too high or too low albedos. Again, models tend to simulate spatially too uniformly distributed surface albedo compared to CLARASAL.

In August, the satellite product produces grid-cell average albedo values between 0.5 and 0.6 over most of the icecovered part of the Arctic and thus smaller spatial variations as in June and July. Also, most of the models show small spatial variability and a relatively uniform distribution of surface albedo in August. However, the surface albedo strongly differs among individual models. The mean surface albedo of the ice-covered ocean areas varies between about 0.3 in GISS-E2-R and 0.75 in MIROC5. A part of this spread can be explained by many more open water areas in the models with lower surface albedo (Fig. 2). In addition, freeze-up starts already in August in a number of models, leading to increased albedo compared to CLARA-SAL.

\subsection{Sea ice albedo}

As already discussed, the surface albedo depends on the sea ice concentration and does not allow for a proper comparison between models and between models and observations since a number of processes affect the ice conditions. Thus, in the following, we focus on the albedo of the ice-covered part of each grid box.

The mean summer ice albedo in CLARA-SAL reaches up to 0.7 between the North Pole and the north coasts of Greenland and Ellesmere Island (Fig. 5). It drops first slightly towards lower latitudes and then rapidly near the ice edges and coasts. Here, ice albedo reaches average summer values below 0.4. The ensemble mean of the CMIP5 models compares well to the satellite data in the central Arctic. It reproduces both the area of maximum albedo as well as the slight reduction towards lower latitudes. However, the ensemble mean does not simulate the observed reduction of ice albedo from the central Arctic towards the ice edges and coastlines. At the coasts, values are 0.58-0.62 in the CMIP5 mean and thus much higher than in CLARA-SAL.

Individual models simulate a large range of summer sea ice albedos, although the range is slightly reduced compared to the surface albedo (compare Fig. 4). The spatial distribution of the observed sea ice albedo is not well reproduced in most models. Only 9 (CanCM4, CanESM2, FGOALS-g2, GFDL-CM3, GFDL-ESM2M, MPI-ESM-LR, MPI-ESM-MR, MRI-CGCM3, NorESM1-M) out of the 21 models are able to simulate an ice albedo distribution that is characterized by an albedo gradient between the area north of Greenland and the Canadian Archipelago and the coasts and ice edges as shown by CLARA-SAL. However, most of these nine models still underestimate the gradient or simulate too high albedo values in the entire Arctic. Three models (ACCESS1-3, EC-Earth, CNRM-CM5) show quite similar albedo values in most of the Arctic but at least a slight tendency to smaller values at the edges. Another seven models simulate almost the same ice albedo in the entire Arctic (CMCC-CESM, CSIRO-Mk3-6-0, GISS-E2-R, 


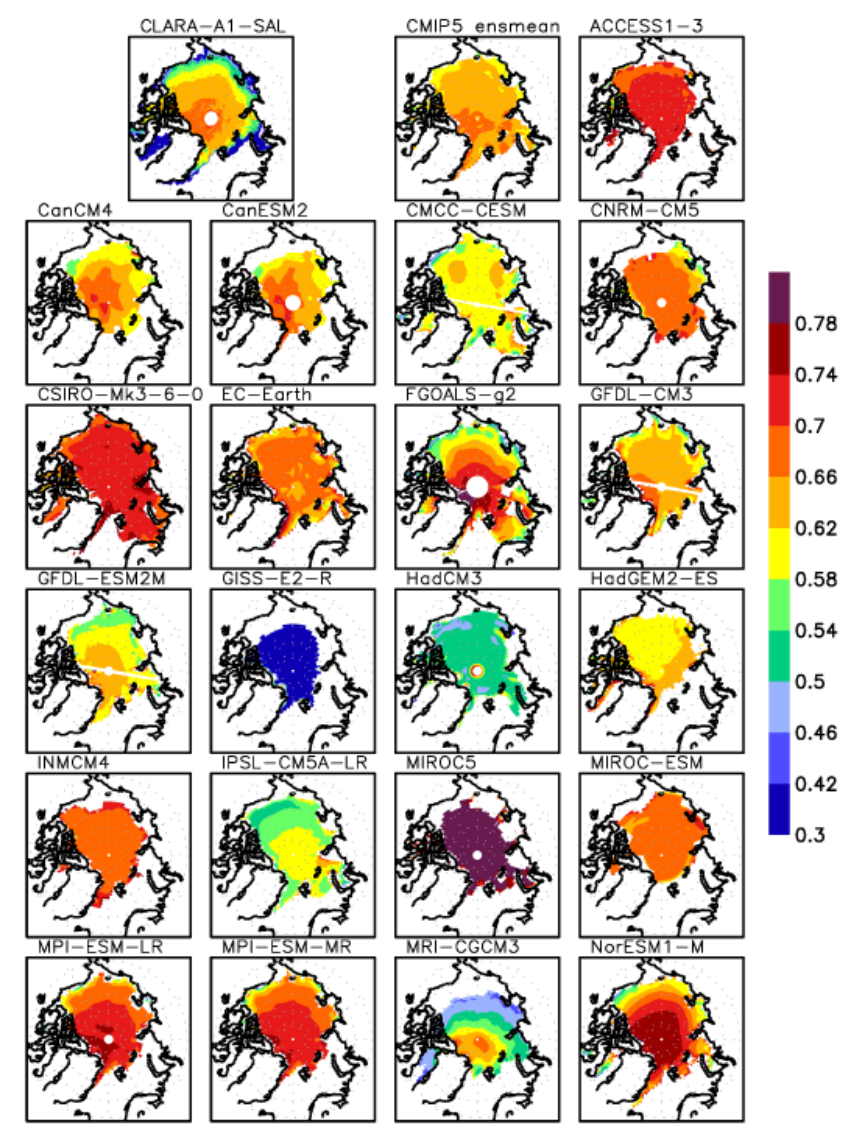

Fig. 5. Summer-averaged (JJA) sea ice albedo, as derived from the satellite data and the CMIP5 model ensemble. Shown is the time average over 1982-2005.

HadCM3, INMCM4, MIROC5, MIROC-ESM). HadGEM2ES and particularly IPSL-CM5A-LR show highest ice albedos in the Atlantic sector of the Arctic and slightly lower in the Pacific sector.

In June (not shown), most models - except for four - still show relatively high albedos compared to the summer mean with values between 0.6 along the ice edges and 0.8 in the interior of the Arctic. This compares to CLARA-SAL values between 0.5 and 0.8. In July, CLARA-SAL data show a strong ice albedo reduction in the entire Arctic Basin, but the large gradient from the North Pole/Greenland region towards the ice edges still exists. The CMIP5 ensemble mean shows slightly lower values in the central Arctic but higher ice albedos near the ice edges compared to CLARA-SAL and thus, as in June, strongly underestimates the spatial gradient in the Arctic. In August, CLARA-SAL ice albedo reaches its minimum while it starts to increase again in the CMIP5 ensemble mean.

The standard deviation of summer mean ice albedo for the period 1982-2005 is shown in Fig. 6. CLARA-SAL shows smallest summer-to-summer variations north of the Canadian Archipelago and largest variations along the ice edges

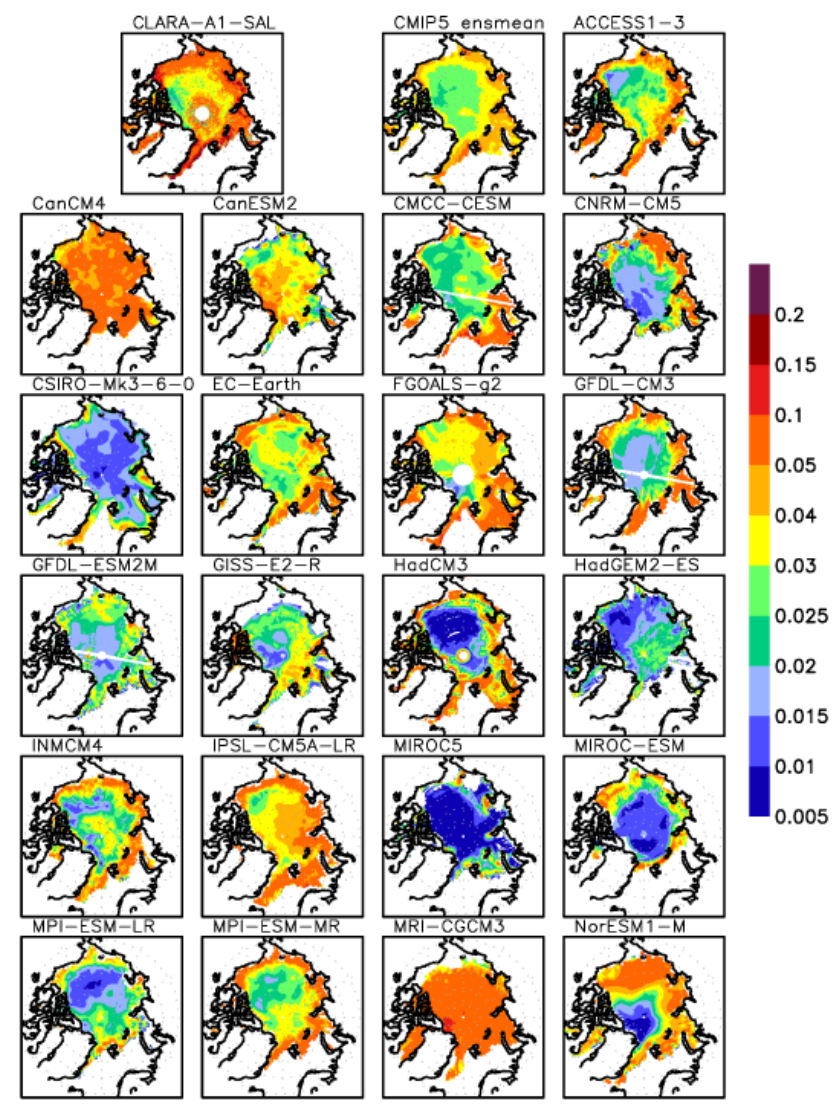

Fig. 6. Standard deviation of summer-averaged (JJA) sea ice albedo in CLARA-SAL, the CMIP5 ensemble mean and the individual CMIP5 models. Shown is the time average over 1982-2005.

and coastlines where values up to 0.1 are reached. As shown above, spatial variations of ice albedo are largest near the ice edge, and the strongly varying position of the ice edge between summers can explain the large standard deviation here. Results from Perovich and Polashenski (2012), analyzing $4 \mathrm{yr}$ of albedo observations near Barrow, further indicate that the year-to-year variations are largest in the melt period. Thus, a longer melt period near the ice edge and coastlines compared to the central Arctic might contribute to large summer albedo variations in these regions.

The model ensemble mean shows, similar to CLARASAL, strongest temporal variations of the sea ice albedo along the coasts and ice edges. However, the variations are generally smaller than in CLARA-SAL. The standard deviation of the ice albedo varies strongly among individual models; models with spatially uniformly distributed ice albedo tend to simulate smaller summer-to-summer variations. This might either indicate that the albedo formulations in these models react less sensitively to variations in the driving parameters or that the temporal and spatial variability of the forcing fields is smaller.

The summer ice albedo trend in CLARA-SAL is relatively small in the interior of the Arctic (Fig. 7 and Table 1) but 


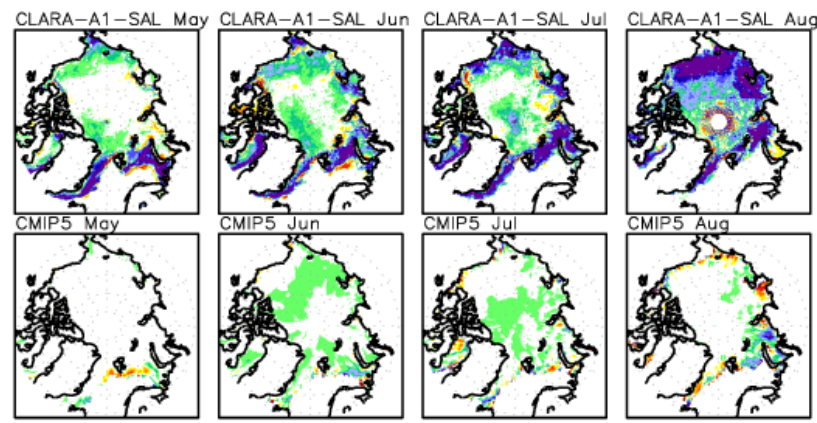

$\begin{array}{llllll}-0.2-0.15-0.1-0.06-0.04-0.020 .02 & 0.04 & 0.06 & 0.1 & 0.15 & 0.2\end{array}$

Fig. 7. Sea ice albedo trend for May, June, July and August in CLARA-SAL and the CMIP5 ensemble mean. Shown is the trend per 24 yr (1982-2005).

strongly negative along the ice edges, particularly in the Pacific sector of the Arctic, in the period 1982-2005. This goes along with a slight northward movement of the ice edge in this period. Between 2005 and 2009 when summer ice reduction accelerated (not shown), CLARA-SAL shows an increased ice albedo reduction, even in the central Arctic. These results agree well to findings by Laine (2004) - showing almost no trend in the central Arctic but slightly negative trends in the surrounding seas for 1982-1997 - and recent results by Riihelä et al. (2013b), indicating an enhanced surface albedo reduction since the mid-1990s. The trend in the CMIP5 models is small compared to the observed one; however, a few models show, similar to the satellite data, a negative trend in larger areas of the Arctic Ocean with ice albedo reductions of 0.1 in the $24 \mathrm{yr}$ period.

Note that we calculated the linear trend in every grid box separately. We did not treat boxes differently where the ice totally disappeared during 1982-2005, which might affect the trend in these boxes. However, only in CLARA-SAL in August, we find some grid points in the Greenland and Barents seas directly at the ice edge with small negative trends (small compared to the trend two or three grid points further into the ice), which might be caused by this problem.

In the models, we find at the ice edge even some areas with slightly positive trends. This is probably due to natural variability. In single extreme years, ice can occur in areas where normally no ice exists. If this happens in the later part of the time period, this leads to a positive ice albedo trend.

\subsection{Ice albedo in the central Arctic}

To avoid comparing effects that are related to different simulations of the ice edge, we focus in the following on the central Arctic Ocean. The ocean area between $80^{\circ} \mathrm{N}$ and $90^{\circ} \mathrm{N}$ shows a relatively high ice concentration in all CMIP5 mod-
Table 1. Ice albedo trend for the period 1982-2005, averaged over $80-90^{\circ} \mathrm{N}$. Trends that are significant at the $95 \%$ significance level are marked bold.

\begin{tabular}{lrrrr}
\hline Trend per 24 yr & Jun & Jul & Aug & JJA \\
\hline ACCESS1-3 & -0.003 & 0.008 & 0.017 & 0.007 \\
CanCM4 & -0.010 & -0.037 & -0.018 & -0.022 \\
CanESM2 & $-\mathbf{0 . 0 5 3}$ & $\mathbf{- 0 . 1 0 2}$ & 0 & $-\mathbf{0 . 0 5 0}$ \\
CMCC-CESM & -0.030 & -0.004 & -0.008 & -0.014 \\
CNRM-CM5 & -0.016 & -0.001 & 0.009 & -0.003 \\
CSIRO-Mk3-6-0 & $-\mathbf{0 . 0 1 8}$ & -0.007 & -0.010 & $-\mathbf{0 . 0 1 2}$ \\
EC-Earth & -0.052 & -0.012 & -0.013 & -0.025 \\
FGOALS-g2 & $-\mathbf{0 . 0 2 7}$ & $-\mathbf{0 . 0 8 1}$ & $-\mathbf{0 . 0 7 9}$ & $-\mathbf{0 . 0 6 2}$ \\
GFDL-ESM2M & -0.024 & -0.002 & -0.012 & -0.012 \\
GFDL-ESM2M & -0.024 & -0.002 & -0.011 & -0.012 \\
GISS-E2-R & 0 & -0.003 & 0.034 & 0.01 \\
HadCM3 & 0.003 & 0.005 & 0.004 & 0.004 \\
HadGEM2-ES & -0.017 & 0.001 & 0.014 & -0.001 \\
INMCM4 & -0.008 & -0.011 & -0.011 & -0.010 \\
IPSL-CM5A-LR & -0.026 & -0.012 & 0.007 & -0.010 \\
MIROC5 & -0.022 & -0.009 & $-\mathbf{0 . 0 2 2}$ & $-\mathbf{0 . 0 1 9}$ \\
MIROC-ESM & 0.003 & 0.001 & -0.011 & -0.002 \\
MPI-ESM-LR & 0.002 & -0.021 & 0.003 & -0.005 \\
MPI-ESM-MR & -0.010 & -0.022 & -0.010 & -0.014 \\
MRI-CGCM3 & -0.065 & $-\mathbf{0 . 1 0 3}$ & -0.069 & $-\mathbf{0 . 0 7 8}$ \\
NorESM1-M & -0.006 & -0.025 & $-\mathbf{0 . 0 5 3}$ & $-\mathbf{0 . 0 2 8}$ \\
CMIP5 mean & $-\mathbf{0 . 0 1 9}$ & $-\mathbf{0 . 0 2 1}$ & $\mathbf{- 0 . 0 1 2}$ & $-\mathbf{0 . 0 1 7}$ \\
CLARA-SAL & -0.008 & -0.014 & -0.038 & -0.019 \\
\hline
\end{tabular}

els during the summer (JJA) and allows for a direct comparison between ice albedo and related variables in this area.

Figure 8 shows the summer-averaged sea ice albedo, surface temperature and snow depth, averaged over the ocean points between $80^{\circ} \mathrm{N}$ and $90^{\circ} \mathrm{N}$ between 1982 and 2005. The ice albedo in CLARA-SAL varies substantially from summer to summer and reaches values between 0.62 and 0.69 . The CMIP5 ensemble mean agrees relatively well, but individual models simulate a large range of ice albedos. Most of the models underestimate the temporal variations as expected from Fig. 6.

The trend in the central Arctic (Table 1) is negative both in the satellite data and all models except for two. The CMIP5 ensemble mean shows a significant negative trend in all summer months with the largest reductions in June and July. In contrast, the satellite data indicate almost no trend in June but a substantial - although not significant at the $95 \%$ level - reduction during August. Most individual models show a negative trend in all 3 summer months but with the smallest trend in August. Note that the time series are short, which makes it difficult to identify clear trends, and that trends are only in a few models statistically significant.

In most albedo schemes, surface temperature and snow depth (and cover) play a leading role for the albedo of the ice/snow system. Depending on the degree of sophistication of the albedo scheme, other variables like for example ice 

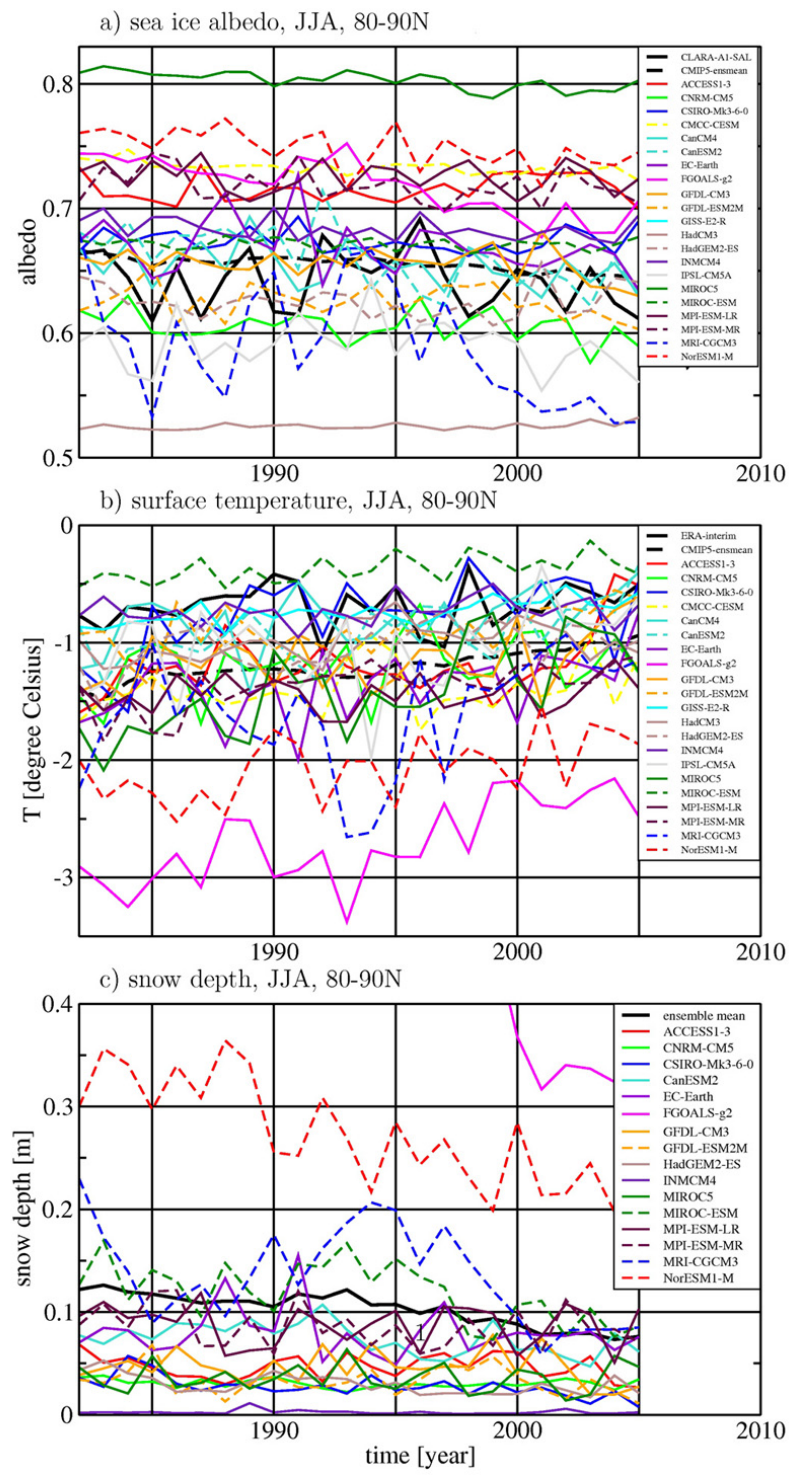

Fig. 8. (a) Summer-averaged (JJA) ice albedo in the central Arctic, averaged over $80-90^{\circ} \mathrm{N}$ for $1982-2005$. (b) The same as (a) but for surface temperature. (c) The same as (a) but for snow depth on ice.

thickness, snow age, melt ponds or flooding play an important role as well. Here, we concentrate on the impact of surface temperature and snow depth on ice albedo in the central Arctic. We chose snow depth instead of snow cover since more CMIP5 models provide snow depth on ice than snow cover. However, for those models providing both depth and cover, they are highly correlated during summer.

Surface temperature is negatively correlated with the ice albedo in the summer. This is particularly the case if surface temperature is near freezing and melting points, and a small change in surface temperature strongly affects the physical properties of the ice/snow system. The highest correlation between surface temperature and ice albedo is found in June,
Table 2. Correlation between ice albedo and surface temperature, averaged over $80^{\circ} \mathrm{N}-90^{\circ} \mathrm{N}$. Correlations that are significant at the $95 \%$ significance level are marked bold.

\begin{tabular}{|c|c|c|c|c|c|}
\hline Correlation coeff. & May & June & July & August & JJA \\
\hline ACCESS1-3 & -0.57 & -0.79 & -0.21 & -0.32 & -0.40 \\
\hline CanCM4 & 0.71 & -0.44 & -0.75 & -0.77 & -0.77 \\
\hline CanESM2 & 0.62 & -0.75 & -0.80 & -0.72 & -0.68 \\
\hline CMCC-CESM & -0.54 & -0.89 & -0.41 & -0.74 & -0.70 \\
\hline CNRM-CM5 & -0.34 & -0.68 & -0.10 & -0.31 & -0.13 \\
\hline CSIRO-Mk3-6-0 & -0.47 & -0.88 & -0.69 & -0.76 & -0.82 \\
\hline EC-Earth & -0.35 & -0.92 & -0.69 & -0.63 & -0.85 \\
\hline FGOALS-g2 & 0.09 & -0.78 & -0.83 & -0.73 & -0.85 \\
\hline GFDL-CM3 & -0.68 & -0.94 & -0.24 & -0.88 & -0.89 \\
\hline GFDL-ESM2M & -0.60 & -0.92 & -0.62 & -0.53 & -0.82 \\
\hline GISS-E2-R & -0.72 & -0.26 & 0.12 & 0.40 & 0.15 \\
\hline HadCM3 & -0.95 & -0.27 & 0.16 & -0.04 & -0.02 \\
\hline HadGEM2-ES & -0.64 & -0.87 & -0.75 & -0.44 & -0.66 \\
\hline INMCM4 & -0.94 & -0.55 & -0.33 & 0.26 & 0.07 \\
\hline IPSL-CM5A-LR & -0.81 & -0.94 & -0.63 & -0.81 & -0.91 \\
\hline MIROC5 & 0.02 & -0.98 & -0.88 & -0.94 & -0.95 \\
\hline MIROC-ESM & -0.33 & -0.95 & -0.01 & -0.93 & -0.82 \\
\hline MPI-ESM-LR & -0.01 & -0.66 & -0.11 & -0.10 & -0.46 \\
\hline MPI-ESM-MR & -0.27 & -0.51 & -0.40 & -0.24 & -0.61 \\
\hline MRI-CGCM3 & -0.72 & -0.87 & -0.78 & -0.79 & -0.91 \\
\hline NorESM1-M & 0.52 & -0.64 & -0.58 & -0.63 & -0.77 \\
\hline CMIP5 mean & -0.33 & -0.74 & -0.45 & -0.51 & -0.61 \\
\hline $\begin{array}{l}\text { CLARA-SAL/ } \\
\text { ERAint }\end{array}$ & 0.53 & -0.43 & -0.23 & -0.38 & -0.61 \\
\hline
\end{tabular}

and almost all models show a high negative correlation (Table 2). In July and August, the correlations are negative in most models, but a few show low or even positive correlations, which mostly are not statistically significant. In May, surface temperature is still much below freezing temperature in many models, which leads to a smaller correlation between temperature and ice albedo in a number of models and also in the ensemble mean.

The CLARA-SAL ice albedo is significantly positively correlated with ERA-Interim surface temperature in May and negatively correlated in June, July and August (not significant at $95 \%$ level in July and August). Similar to the models, the highest negative correlation is found in June, but correlations are smaller than in most models. However, ERAInterim surface temperatures are no observations and ERAInterim and CLARA-SAL do not originate from a consistent data set. Thus, the lower correlation between ERA-Interim surface temperature and CLARA-SAL ice albedo compared to the models does not necessarily indicate that models overestimate the relation between surface temperature and ice albedo.

Snow depth plays an important role in all summer months. All models show a highly positive correlation between snow depth and ice albedo in June and August (Table 3). Correlations in May and July are substantially lower in many models but still positive and often statistically significant. 
Table 3. Correlation between ice albedo and snow depth, averaged over $80-90^{\circ} \mathrm{N}$. Correlations that are significant at the $95 \%$ significance level are marked bold.

\begin{tabular}{lrrrrr}
\hline Correlation coeff. & May & June & July & August & JJA \\
\hline ACCESS1-3 & 0.14 & $\mathbf{0 . 9 1}$ & -0.35 & 0.39 & $\mathbf{0 . 4 8}$ \\
CanESM2 & $\mathbf{0 . 4 3}$ & $\mathbf{0 . 7 2}$ & $\mathbf{0 . 8 8}$ & $\mathbf{0 . 7 3}$ & $\mathbf{0 . 8 2}$ \\
CNRM-CM5 & 0.37 & $\mathbf{0 . 8 3}$ & -0.25 & $\mathbf{0 . 6 1}$ & $\mathbf{0 . 4 7}$ \\
CSIRO-Mk3-6-0 & $\mathbf{0 . 4 3}$ & $\mathbf{0 . 8 7}$ & -0.09 & $\mathbf{0 . 6 0}$ & $\mathbf{0 . 7 2}$ \\
EC-Earth & -0.07 & $\mathbf{0 . 7 8}$ & $\mathbf{0 . 8 7}$ & $\mathbf{0 . 7 3}$ & $\mathbf{0 . 8 5}$ \\
FGOALS-g2 & $\mathbf{0 . 5 9}$ & $\mathbf{0 . 7 6}$ & $\mathbf{0 . 9 2}$ & $\mathbf{0 . 9 3}$ & $\mathbf{0 . 9 4}$ \\
GFDL-CM3 & $\mathbf{0 . 4 7}$ & $\mathbf{0 . 8 7}$ & $\mathbf{0 . 6 3}$ & $\mathbf{0 . 7 1}$ & $\mathbf{0 . 8 8}$ \\
GFDL-ESM2M & $\mathbf{0 . 4 8}$ & $\mathbf{0 . 9 4}$ & 0.28 & $\mathbf{0 . 7 3}$ & $\mathbf{0 . 9 0}$ \\
HadGEM2-ES & 0.30 & $\mathbf{0 . 9 3}$ & $\mathbf{0 . 4 9}$ & $\mathbf{0 . 6 3}$ & $\mathbf{0 . 5 8}$ \\
INMCM4 & $\mathbf{0 . 4 6}$ & 0.05 & -0.30 & 0.21 & -0.04 \\
MIROC5 & 0.18 & $\mathbf{0 . 6 6}$ & $\mathbf{0 . 7 7}$ & $\mathbf{0 . 8 4}$ & $\mathbf{0 . 7 8}$ \\
MIROC-ESM & 0.06 & $\mathbf{0 . 7 7}$ & -0.17 & $\mathbf{0 . 5 7}$ & $\mathbf{0 . 4 9}$ \\
MPI-ESM-LR & $\mathbf{0 . 4 3}$ & $\mathbf{0 . 6 9}$ & $\mathbf{0 . 8 4}$ & $\mathbf{0 . 8 6}$ & $\mathbf{0 . 8 2}$ \\
MPI-ESM-MR & -0.05 & $\mathbf{0 . 6 2}$ & $\mathbf{0 . 9 4}$ & $\mathbf{0 . 8 8}$ & $\mathbf{0 . 9 0}$ \\
MRI-CGCM3 & $\mathbf{0 . 4 0}$ & $\mathbf{0 . 8 4}$ & $\mathbf{0 . 9 3}$ & $\mathbf{0 . 9 6}$ & $\mathbf{0 . 9 3}$ \\
NorESM1-M & 0.26 & $\mathbf{0 . 5 2}$ & $\mathbf{0 . 7 8}$ & $\mathbf{0 . 8 0}$ & $\mathbf{0 . 7 1}$ \\
CMIP5 mean & 0.31 & $\mathbf{0 . 7 4}$ & $\mathbf{0 . 4 5}$ & $\mathbf{0 . 7 0}$ & $\mathbf{0 . 7 0}$ \\
\hline
\end{tabular}

The summer evolution of ice albedo, surface temperature and snow depth in the central Arctic, averaged over the $24 \mathrm{yr}$ period, is shown in Fig. 9. The spread in sea ice albedo among models is relatively small in May, with values around 0.8 in almost all models except for two showing a substantial lower albedo. CLARA-SAL indicates an ice albedo of slightly below 0.8 in May. All models show an albedo reduction in June and July with an increasing spread among models; the ensemble mean is lower than in CLARA-SAL in June but agrees well in July. In August, almost all models simulate an increasing ice albedo, which is in contrast to CLARA-SAL, showing a further ice albedo reduction.

The surface temperature in the central Arctic shows the largest spread among models in May. In June and particularly July, spread is strongly reduced and all models simulate surface temperatures slightly below $0{ }^{\circ} \mathrm{C}$. In August, temperature starts to fall and the spread among models increases again. The model ensemble mean is slightly warmer (colder) than ERA-Interim in June (August), which might explain the different development of ice albedo in models and CLARASAL. This assumes, however, that ERA-Interim provides a more realistic temperature evolution throughout the summer than the models.

The snow depth varies between $20 \mathrm{~cm}$ and $40 \mathrm{~cm}$ in most models in May, is strongly reduced in June, and only very little snow is left in July and August. This is in relatively good agreement with the snow depth climatology from Warren et al. (1999), who proposed a slightly larger snow depth of about $35 \mathrm{~cm}$ in May, $30 \mathrm{~cm}$ in June, $10 \mathrm{~cm}$ in July and $5 \mathrm{~cm}$ in August. However, the results of Warren et al. (1999) are based on data from the period 1954-1991.
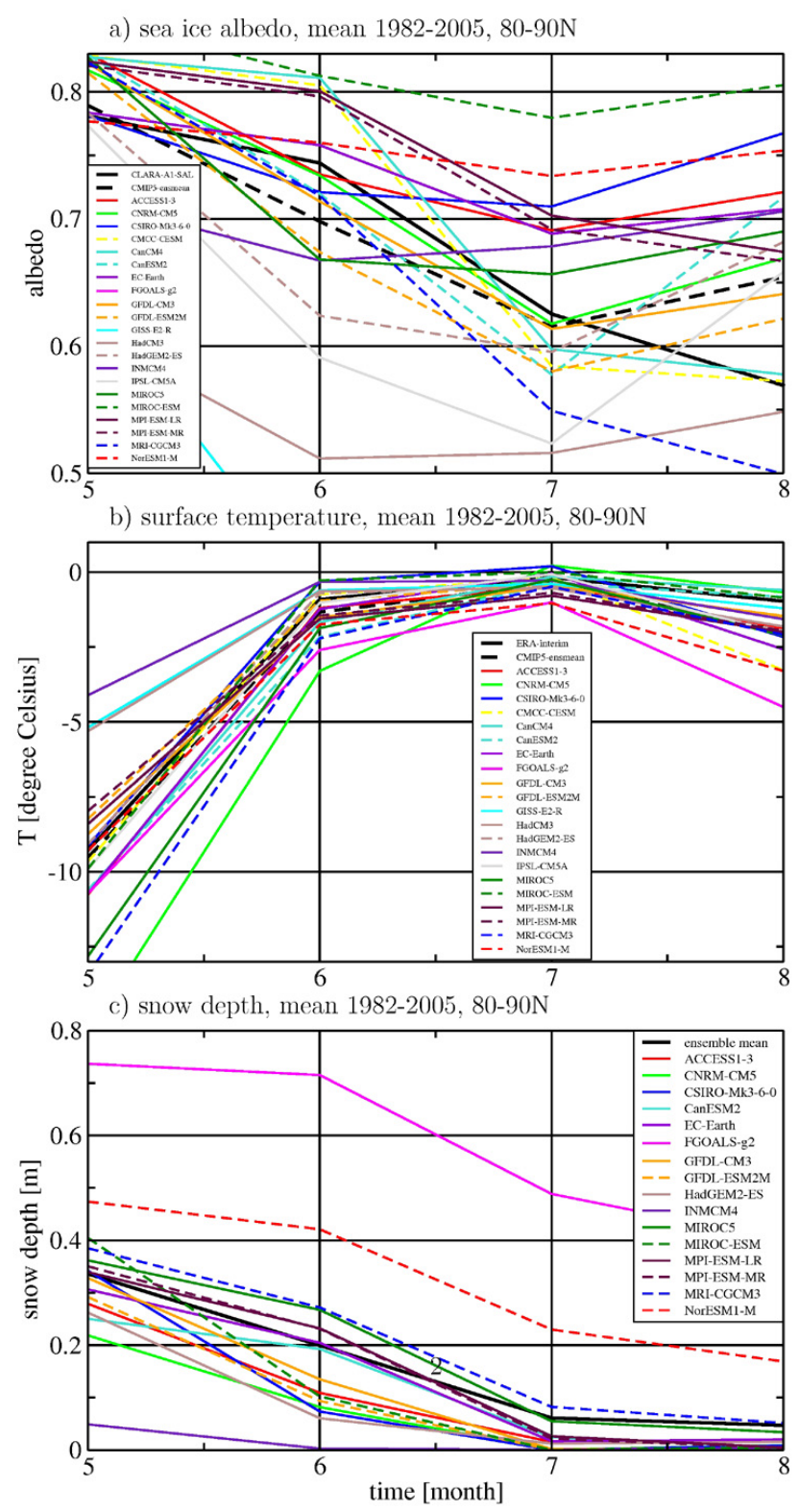

Fig. 9. (a) Time evolution of sea ice albedo through May to August, averaged over $80-90^{\circ} \mathrm{N}$ and $1982-2005$. (b) The same as (a) for surface temperature. (c) The same (a) for snow depth.

\section{Discussing the impact of ice albedo spread among models}

The large spread among simulated ice albedos in the CMIP5 models is one important contributor to the large uncertainties in model simulations of both present-day climate and future climate conditions in the Arctic. Different ice albedos have a direct effect on the absorption of solar radiation at the ice surface. Given the same downward solar radiation at the surface, a smaller ice albedo will reduce the reflection and thus increase the net surface solar radiation flux. As a 


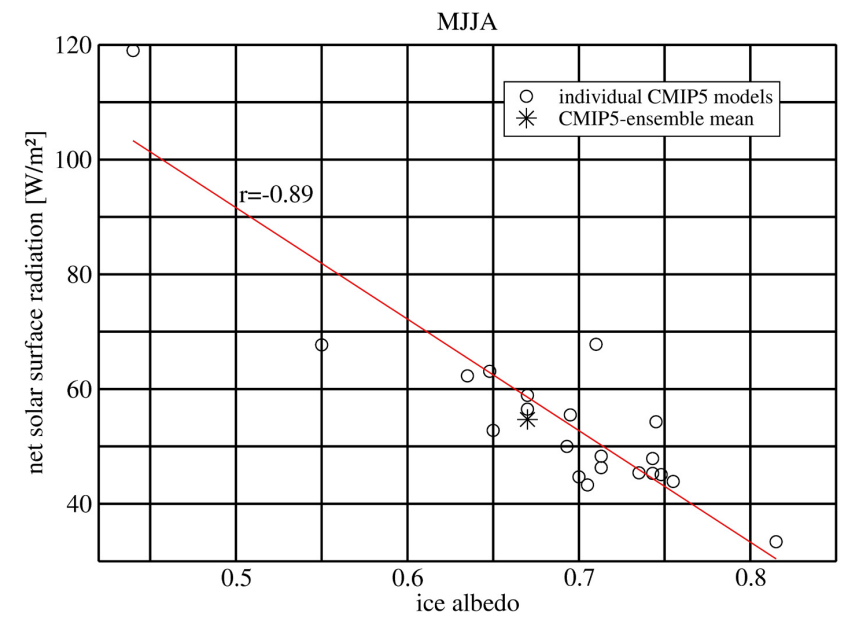

Fig. 10. Relation between summer (MJJA) mean sea ice albedo and net solar surface radiation flux of the ice-covered area averaged over $80-90^{\circ} \mathrm{N}$.

consequence, more ice is reduced, which further reduces the surface albedo. This relation between ice albedo and net solar surface radiation flux is clearly reflected in the CMIP5 models (Fig. 10). Net solar surface radiation flux is highly correlated with the ice albedo in the central Arctic. The downward solar radiation is of course also influenced by absorption and reflection processes in the atmosphere. Thus, the downward solar surface radiation flux differs among models; summer (MJJA) average values vary between roughly $150 \mathrm{~W} \mathrm{~m}^{-2}$ and $205 \mathrm{~W} \mathrm{~m}^{-2}$. However, no clear relation exists between ice albedo and downward solar radiation flux.

Karlsson and Svensson (2013) argued that the ice albedo strongly affects the surface cloud radiative effect and thus not only the shortwave but also the longwave radiation. They stated that "models with a high sea-ice albedo have a smaller cloud albedo effect than those models having less reflective sea-ice surface". This also has implications for the behavior of the models in a changing climate, and the large spread in simulated ice albedos affects the response of the energy budget to climate change.

The strong impact of the albedo on the surface energy budget should affect sea ice conditions, and indeed Karlsson and Svensson (2013) showed that the annual amplitude of average Arctic sea ice concentration is higher in models with low summer ice albedos than in models with high summer ice albedo. However, they did not find any significant relation between ice albedo and trends and absolute values of the ice concentration. We extended this analysis to ice thickness in the Arctic, but we did not find any significant relation between September Arctic ice volume and summer sea ice albedo either. However, models with extremely low and high ice albedo tend to simulate thin and thick ice, respectively. This can also be seen comparing Figs. 3 and 5. Hodson et al. (2013) divided the CMIP3 model ensemble into two groups of models with high and low ice albedo and showed that the simulated mean Arctic ice volumes differed significantly between these two groups.

\section{Summary and conclusions}

This study focused on evaluating spatial and temporal variations of Arctic summer ice albedo in the CMIP5 models using satellite observations (CLARA-SAL) of surface albedo for the period 1982-2005.

The summer sea ice concentration and thickness distributions in the Arctic strongly vary among the CMIP5 models. Even some of those models showing a realistic September Arctic ice extent do not necessarily simulate realistic spatial ice distributions. This leaves doubts about the reliability of sea ice development in future projections and indicates the importance of analyzing spatial fields in addition to integrative time series.

We extracted the ice albedo from the surface albedo by taking the ice concentration into account and assuming a constant surface albedo for the ice-free part. The summer sea ice albedo varies substantially among CMIP5 models, and many models show large biases compared to the CLARASAL product. The CMIP5 ensemble mean, however, agrees relatively well to the satellite data.

The ice albedo is too uniformly distributed in most models and overestimated at the ice edge. This is very likely a deficiency in the parameterization of the albedo of the ice/snow system. In contrast to the ice albedo, the spatial pattern of the surface temperature shows an increase near the ice edge in most CMIP5 models. However, the response of the sea ice albedo to this increase is obviously not sufficient to simulate the observed large ice albedo decrease. Although we did not analyze the albedo parameterizations of the individual models, many models seem to have a minimum ice albedo that is too high compared to the ice albedo found by satellites and direct measurements (Perovich and Polashenski, 2012), and they do not have any or only simplistic melt pond parameterizations. Thus, only few models are able to simulate ice albedos below about 0.5 . The overestimated albedo near the ice edge might lead to reduced summer ice melt in the models compared to reality due to an underestimated ice-albedo feedback. This might contribute to the problem that many global models have no reproduced the observed rapid sea ice reduction in the last decade (Stroeve et al., 2007; Stroeve et al., 2012; Massonnet et al., 2012).

In addition, the CMIP5 models are not fully able to reproduce the albedo evolution throughout the summer. The ice albedo is smaller in most CMIP5 models in June compared to CLARA-SAL. On the other hand, it starts to increase in the models already in August when it reaches its minimum in CLARA-SAL. To which degree the ice albedo parameterizations themselves are responsible for this shift in annual cycle remains unclear. We found that also surface temperature 
shows the same shift compared to ERA-Interim, which might indicate that larger scale climatic conditions are responsible, but it cannot be ruled out that too low (high) albedo in June (August) in the models contributes to the too warm (cold) conditions.

The summer sea ice albedo in CMIP5 models is governed by surface temperature and snow conditions, particularly during the period of melt onset in early summer and refreezing in late summer.

The summer surface solar radiation absorption of the icecovered Arctic areas is strongly affected by the ice albedo and strongly varies among CMIP5 models. The impact of the ice albedo on the sea ice conditions in the CMIP5 models is not clearly visible, indicating the importance of other processes like, for example, large-scale atmospheric and oceanic circulation patterns for the sea ice conditions. Furthermore, this relation might be masked by the fact that melting ice albedo is often used as tuning parameter to overcome other model shortcomings in the Arctic.

The results from this study do not necessarily indicate which model has the most realistic albedo scheme since the albedo is governed by parameters like surface temperature and snow conditions, which are affected by large-scale model climate conditions. If a model is generally too cold (too warm) in the Arctic, we would expect a too high (too low) surface albedo in this model, which leads to positive feedbacks with even colder (warmer) conditions. The Arctic climate system can thus not correctly be simulated (other than with compensating errors) if the large-scale atmospheric and oceanic circulation determining the input of mass, heat and momentum into the Arctic is not correctly simulated. Strong tuning of the albedo in order to achieve realistic Arctic ice and climate conditions in 20th century simulations might lead to unrealistic amplification rates in future simulations.

To improve albedo parameterization further, comprehensive observational data sets are needed to force the albedo scheme, test improvements and to evaluate the results.

Acknowledgements. This study has been made possible by support of the Rossby Centre at the Swedish Meteorological and Hydrological Institute (SMHI) together with the Swedish National Space Board financed project "Utilisation of Advanced Satellite and In situ Observations in Support of Arctic Climate Simulations" and the Swedish Research Council Formas financed project ADSIMNOR.

We acknowledge the World Climate Research Programme's Working Group on Coupled Modelling, which is responsible for CMIP, and we thank the modeling groups for producing and publishing their model output. For CMIP the US Department of Energy's Program for Climate Model Diagnosis and Intercomparison provides coordinating support and led development of software infrastructure in partnership with the Global Organization for Earth System Science Portals.

Edited by: J.-Y. C. Chiu

\section{References}

ACIA: Arctic climate impact assessment, Cambridge University Press, Cambridge, UK, 1042 pp., 2005.

Belchansky, G. I., Douglas, D. C., and Platonov, N. G.: Fluctuating Arctic sea ice thickness changes estimated by an in-situ learned and empirically forced neural network model, J. Climate, 21, 716-729, doi:10.1175/2007JCLI1787.1, 2008.

Bintanja, R., Graversen, R. G., and Hazeleger, W.: Arctic winter warming amplified by the thermal inversion and consequent low infrared cooling to space, Nat. Geosci. Lett., 4, 758-761, doi:10.1038/NGEO1285, 2011.

Comiso, J. C., Parkinson, C., Gersten, R., and Stock, L.: Accelerated decline in the Arctic sea ice cover, Geophys. Res. Lett., 35, L01703, doi:10.1029/2007GL031972, 2008.

Dee, D. P., Uppala, S. M., Simmons, A. J., Berrisford, P., Poli, P., Kobayashi, S., Andrae, U., Balmaseda, M. A., Balsamo, G., Bauer, P., Bechtold, P., Beljaars, A. C. M., van de Berg, L., Bidlot, J., Bormann, N., Delsol, C., Dragani, R., Fuentes, M., Geer, A. J., Haimberger, L., Healy, S. B., Hersbach, H., Holm, E. V., Isaksen, L., Kållberg, P., Köhler, M., Matricardi, M., McNally, A. P., Monge-Sanz, B. M., Morcrette, J. J., Park, B. K., Peubey, C., de Rosnay, P., Tavolato, C., Thepaut, J. N., and Vitart, F.: The ERA-Interim reanalysis: configuration and performance of the data assimilation system, Q. J. Roy. Meteor. Soc., 137, 553-597, doi:10.1002/qj.828, 2011.

Devasthale, A., Sedlar, J., Koenigk, T., and Fetzer, E. J.: The thermodynamic state of the Arctic atmosphere observed by AIRS: comparisons during the record minimum sea ice extents of 2007 and 2012, Atmos. Chem. Phys., 13, 7441-7450, doi:10.5194/acp-13-7441-2013, 2013.

Eastwood, S., Larsen, K. R., Lavergne, T., Nielsen, E., and Tonboe, R.: Global sea ice concentration reprocessing: product user manual, Product OSI-409, Version, 1, 2010.

Graversen, R. G. and Wang, M.: Polar amplification in a coupled climate model with locked albedo, Clim. Dynam., 33, 629-643, doi:10.1007/s00382-009-0535-6, 2009.

Graversen, R. G., Mauritsen, T., Tjernström, M., Källén, E., and Svensson, G.: Vertical structure of recent Arctic warming, Nature, 541, 53-56, doi:10.1038/nature06502, 2008.

Guemas, V., Doblas-Reyes, F., Germe, A., Chevallier, M., and Salas y Mélia, D.: September 2012 Arctic sea ice minimum: Discriminating between sea ice memory, the August 2012 extreme storm and prevailing warm conditions, in Explaining Extreme Events of 2012 from a Climate Perspective, B. Am. Meteorol. Soc., 94, S20-S22, 2013.

Hodson, D. L. R., Keeley, S. P. E., West, A., Ridley, J., Hawkins, E., and Hewitt, H. T.: Identifying uncertainties in Arctic climate change projections, Clim. Dynam., 40, 2849-2865, doi:10.1007/s00382-012-1512-z, 2013.

IPCC: Climate Change 2007: The Physical Science Basis, Contribution of Working Group I to the Fourth Assessment Report of the Intergovernmental Panel on Climate Change, edited by: Solomon, S., Qin, D., Manning, M., Chen, Z., Marquis, M., Averyt, K. B., Tignor, M., and Miller, H. L., Cambridge University Press, Cambridge, UK and New York, NY, USA, 2007.

Jakobson, E., Vihma, T., Palo, T., Jakobson, L., Keemik, H., and Jaagus, J.: Validation of atmospheric reanalyses over the central Arctic Ocean, Geophys. Res. Lett., 39, L10802, doi:10.1029/2012GL051591, 2012. 
Karlsson, J. and Svensson, G.: Consequences of poor representation of Arctic sea-ice albedo and cloud-radiation interactions in the CMIP5 model ensemble, Geophys. Res. Lett., 40, 4374-4379, doi:10.1002/grl.50768, 2013.

Karlsson, K.-G., Riihelä, A., Müller, R., Meirink, J. F., Sedlar, J., Stengel, M., Lockhoff, M., Trentmann, J., Kaspar, F., Hollmann, R., and Wolters, E.: CLARA-A1: a cloud, albedo, and radiation dataset from $28 \mathrm{yr}$ of global AVHRR data, Atmos. Chem. Phys., 13, 5351-5367, doi:10.5194/acp-13-5351-2013, 2013.

Koenigk, T. and Brodeau, L.: Ocean heat transport into the Arctic in the twentieth and twenty-first century in EC-Earth, Clim. Dynam., doi:10.1007/s00382-013-1821-x, 2013.

Koenigk, T., Brodeau, L., Graversen, R. G., Karlsson, J., Svensson, G., Tjernström, M., Willen, U., and Wyser, K.: Arctic climate change in 21st century CMIP5 simulations with EC-Earth, Clim. Dynam., 40, 2720-2742, doi:10.1007/s00382-012-1505-y, 2013.

Kwok, R. and Cunningham, G. F.: ICESat over Arctic sea ice: Estimation of snow depth and ice thickness, J. Geophys. Res., 113, C08010, doi:10.1029/2008JC004753, 2008.

Laine, V.: Arctic sea ice regional albedo variability and trends, 1982-1998, J. Geophys. Res., 109, C06027, doi:10.1029/2003JC001818, 2004.

Li, J., Scinocca, J., Lazare, M., McFarlane, N., von Salzen, K., and Solheim, L.: Ocean Surface Albedo and Its Impact on Radiation Balance in Climate Models, J. Climate, 19, 6314-6333, 2006.

Liu, J., Zhang, Z., Inoue, J., and Horton, R. M.: Evaluation of snow/ice albedo parameterizations and their impacts on sea ice simulations, Int. J. Climatol., 27, 81-91, doi:10.1002/joc.1373, 2007.

Liu, Y., Key, J. R., and Wang, X.: The influence of changes in cloud cover on recent surface temperature trends in the Arctic, J. Climate, 21, 705-715, 2008.

Lüpke, C., Vihma, T., Jakobson, E., König-Langlo, G., and Tetzlaff, A.: Meteorological observations from ship cruises during summer to the central Arctic: A comparison with reanalysis data, Geophys. Res. Lett., 37, L09810, doi:10.1029/2010GL042724, 2010.

Markus, T., Stroeve, J. C., and Miller, J.: Recent changes in Arctic sea ice melt onset, freezeup, and melt season length, J. Geophys. Res., 114, C12024, doi:10.1029/2009JC005436, 2009.

Massonnet, F., Fichefet, T., Goosse, H., Bitz, C. M., PhilipponBerthier, G., Holland, M. M., and Barriat, P.-Y.: Constraining projections of summer Arctic sea ice, The Cryosphere, 6, 13831394, doi:10.5194/tc-6-1383-2012, 2012.

Perovich, D. K. and Polashenski, C.: Albedo evolution of seasonal Arctic sea ice, Geophys. Res. Lett., 39, L08501, doi:10.1029/2012GL051432, 2012.

Richter-Menge, J. and Jeffries, M.: The Arctic, in "State of the Climate in 2010", B. Am. Meteorol. Soc., 92, S143-S160, 2011.
Riihelä, A., Laine, V., Manninen, T., Palo, T., and Vihma, T.: Validation of the Climate-SAF surface broadband albedo product: Comparison with in situ observations over Greenland and the icecovered Arctic Ocean, Remote Sens. Environ., 114, 2779-2790, doi:10.1016/j.rse.2010.06.014, 2010.

Riihelä, A., Manninen, T., Laine, V., Andersson, K., and Kaspar, F.: CLARA-SAL: a global $28 \mathrm{yr}$ timeseries of Earth's black-sky surface albedo, Atmos. Chem. Phys., 13, 3743-3762, doi:10.5194/acp-13-3743-2013, 2013a.

Riihelä, A., Manninen, T., and Laine, V.: Observed changes in the albedo of the Arctic sea-ice zone for the period 1982-2009, Nat. Clim. Change, 3, 895-898, doi:10.1038/NCLIMATE1963, 2013b.

Rothrock, D. A., Zhang, J., and Yu, Y.: The Arctic ice thickness anomaly of the 1990s: a consistent view from observations and models, J. Geophys. Res., 108, 3083, doi:10.1029/2001JC001208, 2003.

Serreze, M. C., Barrett, A. P., Stroeve, J. C., Kindig, D. N., and Holland, M. M.: The emergence of surface-based Arctic amplification, The Cryosphere, 3, 11-19, doi:10.5194/tc-3-11-2009, 2009.

Spielhagen, R. F., Werner, K., Aagaard Sörensen, S., Zamelczyk, K., Kandiano, E., Budeus, G., Husum, K., Marchitto, T. M., and Hald, M.: Enhanced Modern Heat Transfer to the Arctic by Warm Atlantic Water, Science, 331, 450-453, doi:10.1126/science.1197397, 2011.

Stroeve, J. C., Holland, M. M., Meier, W., Scambos, T., and Serreze, M. C.: Arctic sea ice decline: faster than forecast, Geophys. Res. Lett., 34, L09501, doi:10.1029/2007GL029703, 2007.

Stroeve, J. C., Serreze, M. C., Holland, M. M., Kay, J. E., Malanik, J., and Barret, A. P.: The Arctic's rapidly shrinking sea ice cover: a research synthesis, Clim. Change, 110, 1005-1027, doi:10.1007/s10584-011-0101-1, 2012.

Utall, T., Curry, J. A. , McPhee M.G., and Perovich, D. K., Moritz, R. E., Maslanik, J. A., Gust, P. S., Stern, H. L., Moore, J. A., Turenne, R., Heiberg, A., Serreze, M. C., Wylie. D. P., Persson, P. O. G., Paulson, C. A., Halle, C., Morison, J. H., Wheeler, P. A., Makshtas, A., Welch, H., Shupe, M. D., Intrieri, J. M., Stamnes, K., Lindsey, R. W., Pinkel, R., Pegau, W. S., Stanton, T. P., and Grenfeld, T. C.: Surface heat budget of the Arctic Ocean, B. Am. Meteorol. Soc., 83, 255-275, 2002.

Vavrus, S., Holland, M., Jahn, A., Bailey, D., and Blazey, B.: 21stcentury Arctic climate change in CCSM4, J. Climate, 25, 26962710, doi:10.1175/JCLI-D-11-00220.1, 2012.

Warren, S. G., Rigor, I. G., Untersteiner, N., Radionov, V. F., Bryazgin, N. N., and Aleksandrov, Y. I.: Snow Depth on Arctic Sea Ice, J. Climate, 12, 1814-1829, 1999.

Winton, M.: Amplified Arctic climate change: What does surface albedo feedback have to do with it?, Geophys. Res. Lett., 33, L03701, doi:10.1029/2005GL025244, 2006. 